\title{
Experiencias de alteridad. Lo fantasmático y lo poético en Derrida
}

\author{
SOL ANAHÍ VIÑOLO Universidad Nacional de Córdoba - CONICET, Argentina
}

ORCID 0000-0001-7057-2715

\section{Resumen}

Según Derrida, tanto en lo fantasmático como en la poesía se hace la misma experiencia de la alteridad, de lo otro, lo extraño y más allá de lo humano. En este trabajo se busca ahondar en esta afirmación analizando, por un lado, la satisfacción fantasmática de la pulsión de poder, desde la lectura derridiana del psicoanálisis, como la condición de posibilidad de la soberanía, y, por el otro, la poesía, desde la concepción de la poética celaniana que Derrida retoma en La bestia y el soberano.

\section{Palabras clave: Jacques Derrida / logos / figura / experiencias de alteridad / poesía / fantasma}

\begin{abstract}
Experiences of otherness. The phantasmic and the poetic in Derrida Abstract

According to Derrida, both in the phantasmatic and in poetry the same experience of otherness, of the other, of the unknown and of what is beyond humans, is made. This paper seeks to delve into this statement by analyzing, on the one hand, the phantasmatic satisfaction of the power drive, from the Derridian reading of psychoanalysis, as the condition for the possibility of sovereignty, and, on the other hand, poetry, from the conception of Celanian poetics that Derrida takes up in The Beast and the Sovereign.
\end{abstract}

Key words: Jacques Derrida / logos / figure / experiences of otherness / poetry / phantasm

\section{Introducción}

La bestia y el soberano es el último seminario que impartió Jacques Derrida en la École des Hautes Études en Sciences Sociales de París entre los años 2001 y 2003, publicados póstumamente con el mismo nombre. Allí, Derrida analiza la historia política y ontoteológica (haciendo referencia al logos como fundamento) del concepto y las figuras de la soberanía, entendiendo a esta como ipseidad (coincidencia con sí) y, por lo tanto, como la negación de la differance, que es, para el autor, la estructura de todas las cosas.

Recibido: 20/4/2021. Aceptado: 4/6/2021

Para citar este artículo: Viñolo, S.A. (2021). Experiencias de alteridad. Lo fantasmático y lo poético en

DOI: 10.14409/tb.2021.14.eoo47 
Según Derrida (2010), la arqueología del logos político se convierte en una "anarqueología», porque al final con lo que nos encontramos es con el abismo intrínseco al logos, un vacío inherente que la lógica por sí misma no puede suturar, necesitando para ello de un dispositivo figurativo que le permita evitar la caída en su abismo o enmascararla. Lo figural surge así para solucionar este abismo del logos político actuando con una lógica de la simulación, diferente a la lógica del logos (razón que se quiere pura), posibilitando que las cosas parezcan diferentes de lo que son; condición, al mismo tiempo, de posibilidad y de imposibilidad del logos político, pues la única manera en la que se puede manifestar el ipsocentrismo lógico es mediante la simulación figurativa. Ahora bien, esta figura según Derrida, es un fantasma, en el sentido del psicoanálisis. Es decir, que si la figura sutura el abismo del logos político al que este se va a caer en el momento de realizar su propia teleoescatología y tratar de ser lo que es, o sea una entidad que se abstrae de su propia materialidad, es porque funciona de una manera fantasmática.

Asimismo, en La bestia y el soberano (2010), Derrida retoma la poética celaniana, que piensa la poesía como un camino, que no es tanto algo que "es» en cuanto un acontecimiento, la venida de un acontecimiento que evoca la oscuridad propia de la poesía como el lugar de un encuentro por venir desde el horizonte de lo lejano y de lo extranjero. Y afirma que la experiencia de lo poético es la misma que en lo fantasmático, porque en ambas se hace la misma experiencia de la alteridad, de lo otro, lo extraño y más allá de lo humano. Es sobre esta afirmación que se inspira este artículo y en la que se busca ahondar, analizando, por un lado, la satisfacción fantasmática de la pulsión de poder de la soberanía — que es para Derrida el fundamento de la historia ontoteológica y política que aborda en La bestia y el soberano-, desde la lectura derridiana del psicoanálisis y, por el otro, la poesía a partir de la poética celaniana que retoma Derrida como paradigma de la poesía.

\section{Ipseidad, soberanía y logos político}

Ipseidad (del latín, coincidencia con sí mismo), es el término que Derrida (2010) utiliza para describir la soberanía como una instancia de presencia en sí, que no tiene adentro ninguna differance, que es para el autor la estructura de todas las cosas y que, por lo tanto, la soberanía sería la negación de dicha estructura.

El fundamento que permite satisfacer la soberanía — que, según Derrida, es el meta-concepto capital de la historia ontoteológica-, es un concepto lógico, un logos, pero entendido en un sentido logofonocéntrico, es decir, en una interpretación particular que ha sido desarrollada en el marco de la tradición filosófica occidental, según la cual el logos es una phoné en la que se expresa el pensamiento presente a sí mismo como pura idealidad. Derrida llama «historia ontoteológica política» a esta tradición filosófica, haciendo referencia de esta manera al concepto del logos como fundamento, retomando el concepto de «ontoteología» que Heidegger utiliza para referirse al gesto con el que en la historia de la filosofía se ha reducido el ser al ente presente, 0 sea, un ente que tiene una esencia (onto) y que ha sido reducido a Dios (teología).

El comienzo del Evangelio de Juan: «Al comienzo era el verbo (logos) y el logos era Dios», confirma, según Derrida, las primeras palabras del Génesis, donde al decir "Que se haga la luz», Dios hizo con la palabra que la luz se hiciese. Con lo cual, Arché es aquí igual al logos, el logos que crea, que hace venir o advenir y que crea al ser vivo, el logos evangélico que habla en efecto de un origen del mundo creado por el soberano, Dios. 
¿Cómo no el logos, el logos mismo, sino el logos determinado, interpretado, sobreentiéndase travestido, disfrazado, casi podría decirse corrompido bajo la apariencia de la razón y del entendimiento, el logos como razón y entendimiento, de hecho como «lógica», cómo, bajo ese disfraz o bajo esa apariencia, llega a dominar al ser, a tornarse más fuerte que el ser, desde el inicio de la filosofía griega? (Derrida, 2010:327)

Se trata — prosigue Derrida — de una soberanía violentamente impuesta del logos como razón, entendimiento, lógica; una fuerza de la razón que mete en razón a otras interpretaciones del logos, de la palabra o del léxico, como una especie de guerra y conflicto donde la razón vence por fuerza con la razón —el racionalismo de lo que vendrá a inscribirse más tarde en el concepto de animal rationale o de zôon logon echon- Lo que no significa que esa fuerza superior de la razón lógica haya vencido a un pensamiento del logos que fuese ajeno a toda fuerza, sino que se trata de un conflicto entre más de una fuerza, «en donde la fuerza está del lado de la razón y vence, un poco como "la razón del más fuerte"» (2010:372).

La interpretación del logos de Juan, con influencia filosófica greco-judía y del judaísmo helenístico, que designa un único ente particular, el hijo de Dios, en su función de mediador entre Dios y los humanos, el ser vivo que posee el logos — definición que ha regido, según Derrida, en toda la tradición occidental—, es en sí misma un ejercicio de fuerza o violencia. Cuando Juan, al interpretar justamente el logos como mediación, traduce e identifica el logos con Cristo, existe ahí mismo una operación de soberanía, de fuerza que viene a vencer a otra fuerza. «No se trata de filólogos que, solos, deciden traducir, interpretar el logos como Cristo, mediador, sino que es toda la fuerza histórica la que está en marcha para producir dicha traducción» (2010:393).

Si la historia de la ontoteología política ha sido considerada siempre en la tradición occidental como una historia de logos porque su fundamento es un fundamento lógico; existen, sin embargo, siguiendo a Derrida, otros elementos meta-lógicos y meta-filosóficos que no han sido considerados o que han sido subestimados en esta historia como son los tropos, las figuras, las metáforas, las imágenes, etc., con lo cual esta historia no es una historia solo de logos, sino también una historia de figuras. Para demostrar esto, en el seminario La bestia y el soberano, Derrida desarrolla una analogía sobrecargada entre una bestia y un soberano que se supone que comparten el lugar de cierta exterioridad con respecto a la «ley» y al «derecho» (fuera de la ley, por encima de las leyes, origen y fundamento de la ley), realizando una suerte de taxonomía de las figuras animales con las que los seres humanos se cuentan a sí mismos la historia de lo político, fundamentalmente el «personaje» del lobo que aparece en numerosas culturas y épocas, desde Plauto hasta Hobbes y Rousseau, que se representa así mismo como un hombre-lobo. Vale aclarar que Derrida no está haciendo referencia a ningún lobo natural o real, sino que se trata de un término, de una palabra, un animal fabuloso, un otro lobo que la figura fabulosa vendría, como un sustituto, a la vez a anunciar y disimular, a manifestar y enmascarar. Para dar cuenta de esto, Derrida (2010) retoma, en particular, el segundo verso de una fábula de La Fontaine, «El lobo y el cordero», que analiza a lo largo del seminario: «La razón del más fuerte es siempre la mejor:/Vamos a mostrarlo enseguida./ (... ¿Mostrar qué? Pues bien, que "la razón del más fuerte es siempre la mejor"» (106). Proposición violenta y pragmáticamente tautológica, tanto en La Fontaine como en el comienzo mismo del seminario que Derrida anuncia comenzar «a paso de lobo», utilizando, por fuerza de ley, su posición acreditada de profesor autorizado para diferir el momento en el que mostrará o demostrará que la razón del más fuerte es «siempre la mejor», 
demostrándolo de facto, por el hecho mismo de permitirse diferir, en una demostración que es performativa y pragmática al mismo tiempo.

Muestro con el movimiento mismo, haciéndolo, caminando, produciendo el acontecimiento del que hablo o del que anuncio que hablaré, demuestro que la fuerza gana al derecho y determina el derecho, y eso sin dilación. (...) utilizo mi poder, consistente en comenzar de este modo y no de otro, en comenzar por hacerles esperar a ustedes, en diferir, en advertirles que no olviden el lobo, ni el hombre-lobo o el fuera-de-la-ley, en hacerles esperar el momento de mostrar lo que prometo que voy a mostrar y demostrar. La razón del más fuerte está aquí mismo en funcionamiento (...). Como si yo mismo fuese, no lo olvidemos, un lobo, incluso un hombre-lobo. (Derrida, 2010:106)

A partir de este acto performativo, Derrida nos muestra el rasgo mínimo que hay que reconocer en la posición de soberanía, esto es, cierto poder de dictar, asociado a la posicionalidad o autoposicionalidad de sí mismo, ipse, del soberano. Nos dice Derrida: el soberano es alguien que tiene su fin en sí mismo o que es el fin de todo, y esta es la definición esencial de la soberanía.

Asimismo, Derrida (2010) llama la atención, retomando a Benveniste, en la diferencia sexual marcada, al menos por la gramática, entra la y el (la bestia y el soberano) y en la manera en que el soberano aparece casi siempre en la historia asociado a la figura masculina del rey, del amo, del jefe, del padre de familia o del marido — de la ipseidad del ipse, que en su etimología misma implica el ejercicio del poder por parte de alguien que basta con designarse como sí mismo, ipse. El soberano es aquel que tiene el derecho y la fuerza de ser reconocido como sí mismo.

Es Benveniste, según Derrida, quien inscribió el valor de ipseidad en la misma filiación que la noción de «poder» —que está constituida y recibe su forma verbal de la expresión predicativa «pote est» contraída en «potest», que engendra la conjugación possum, potest, «soy capaz, puedo»—, como si el poder le fuese reconocido en primer lugar a aquel al que se podía designar o que podía designarse como «mismo». Así, pues, el concepto de soberanía implicará siempre la posibilidad de esa posicionalidad, de esa tesis de sí o de autoposición de quien plantea o se plantea como ipse. Benveniste prosigue definiendo la soberanía, sin utilizar este término, precisamente como la autoridad del ipse. En ese sentido, la dictadura es siempre la esencia de la soberanía, ligada al poder de decir en forma de dictado, de prescripción, de orden, de decir último o de veredicto performativo que da órdenes y no tiene que rendir cuentas más que ante sí mismo. A su vez, Derrida (2005), retoma la definición de soberano de Schmitt como aquel que tiene derecho a interrumpir el derecho.

Este rasgo mínimo que hay que reconocer en la soberanía, que es este cierto poder de dictar, de hacer pero asimismo de suspender la ley; es decir, el derecho excepcional de situarse por encima del derecho, el derecho al no-derecho, corre el riesgo de llevar al soberano humano por encima de lo humano - hacia la omnipotencia divina - $y$, a la vez, de hacer que el soberano se parezca a la bestia (que desprecia la ley). Esto debe llevar a preguntarnos, según Derrida, sobre esa doble y contradictoria figuración del «hombre político» como, por una parte, superior, en su soberanía misma, a la bestia, a la que domina, somete, domestica o mata, pero, por otra parte, figuración del «hombre político» y, especialmente del Estado soberano, como animalidad. 
animal, y tan pronto (o simultáneamente) como la manifestación de la bestialidad o de la animalidad humana, dicho de otro modo, de la naturalidad humana? (...) Conclusión [nos dice Derrida hacia el final de la primera sesión]: la bestia y el soberano (la pareja, el apareamiento, la cópula), la bestia es el soberano, el hombre es la bestia para el hombre, homo homini lupus, Pedro y el lobo, Pedro acompaña a su abuelo en la caza del lobo, Pedro, el abuelo y el lobo, el padre es el lobo. (Derrida, 2010:52)

Volviendo a la cuestión del logos, ¿por qué si este es el fundamento de la historia ontoteológica política, existe la necesidad de una simulación, de un figura, incluida la figura del lobo? Para contestar esta pregunta, Derrida hace una arqueología del arché del logos político para ver cómo surge la figura al origen del logos.

\section{Anarqueotropología y el abismo del logos}

Lo que se desprende de Canallas (2005) y La bestia y el soberano (2010) es que el logos al origen se caracteriza por ser fuerza, en tanto que el logos o la «racionalidad política» es aquel tipo de racionalidad que tiene que "decidir», lo que se manifiesta en general desde el momento en el que la razón tiene que elegir una manera de empezar, de continuar y concluir que es arbitraria. La razón del más fuerte que opera aquí es, para Derrida, exactamente la racionalidad soberana, el logos político que tiene como objetivo último lo que Schmitt (2009) llama el estado de excepción. Es en este sentido que Derrida, tratando de sacar a luz una estructura paradójica del poder por la cual este está al mismo tiempo adentro y afuera de la ley, analiza a Dios y a la bestia como las dos caras del soberano, en relación con el poder de dictar, de hacer y suspender la ley al mismo tiempo, como un derecho excepcional a situarse por encima del derecho, el derecho al no-derecho.

El hecho de que el logos o la razón tenga una cara existencial (que está en el mundo, en la finitud, en la historia), que busca trascender para ser lo que quiere ser: no finita, fundamento, principio; es el exceso de la razón sobre sí misma, que la metafísica empuja a poner en acto, pues si la racionalidad está en el mundo, en la existencia, para que pueda ser pura - lo que efectivamente quiere ser, o sea una instancia logofonocéntrica que no tiene ninguna vinculación con el mundo-, tiene que trascender su finitud, cortarse de sí, poner un exceso sobre sí misma. Es aquí, cuando la racionalidad trata de romper con esta condición de existencia que es su propia condición, que se vuelve una quimera evanescente, que no existe en ningún lugar, y es entonces que el principio lógico soberano hace experiencia de una división de sí mismo, de un vacío o un el abismo, telos y escato del logos político.

Ahora bien, si la lógica nunca llega a solucionar su propio abismo — porque cuando más intenta ser lo que es (razón que se quiere pura), es cuando más cae dentro de su abismo—, necesita de un dispositivo tal que vaya a suturar este abismo, que es el dispositivo figurativo que permite evitar la caída o enmascararla. Lo figural surge así, de cierta manera, para solucionar este abismo del logos político, actuando con una lógica que no es la lógica del logos, sino una lógica de la simulación, del «como si» fuera posible, que puede hacer que las cosas parezcan diferentes de lo que son. En este sentido, la figura es la condición, al mismo tiempo, de posibilidad y de imposibilidad del logos político: de posibilidad porque sin él no habría logos, que se cumpliría en su teleología abismal; y de imposibilidad, pues si lo figural va a solucionar el abismo del logos, este no va a aparecer como tal, sino mediante «otro», que es lo figural. ${ }^{1}$ Esto significa que la única manera en la que se puede manifestar el ipsocentrismo lógico es mediante la simulación figurativa. Es por ello que, en cuanto al principio, Derrida dice: «No al principio era el Acto, el Verbo, o la Palabra, o 
el Logos, sino la Fábula, de la que, no obstante, es preciso recordar (aunque todavía hablaremos mucho de fábulas) que esa Fábula es, como su nombre indica, ante todo una Palabra» (2010:228).

Si la fábula (figuras retóricas que funcionan produciendo giros semánticos) es lo que soluciona el abismo en el que el logos político se va a caer en razón de su fuerza, el cúlmine de la arqueología no es anarqueológico sino anarqueotropológico, es decir, una historia que continuamente pierde su principio y que trata de solucionar esta pérdida mediante un tropos. Para entender mejor esto es necesario entender qué es una fábula para Derrida. En todo caso, una fábula es siempre y ante todo una narración, una ficción que pretende enseñarnos algo, una ficción que supuestamente hace saber, tanto en el sentido de llevar un saber al conocimiento del otro, de informar al otro; como en el sentido de "hacer saber», de dar la impresión de saber, hacer el efecto del saber, en donde el saber es un presunto saber, un falso saber, un simulacro, una máscara, para lo que es necesario una técnica, una retórica, «un arte del simulacro, un saber-hacer para hacer saber allí donde no hay nada que saber, allí donde no hay saber digno de ese nombre» (Derrida, 2010:58).

Lo fabuloso de la fábula, dice Derrida, no se debe solo a su naturaleza lingüística, al hecho de que esté constituida por palabras, sino que implica también el acto, el gesto, la acción, aunque solo sea la operación que consiste en producir relato, en organizar, en disponer el discurso para contar, para hacer el saber, para hacer performativamente - tal como hacen los medios de comunicación y que Derrida ejemplifica en La bestia y el soberano con el caso del atentado a las torres gemelas. Así, si el discurso político y la acción política que va unida a él, estuviesen constituidos, incluso instaurados por lo fabuloso, la dimensión fabulosa de esa retórica política no estaría limitada a las operaciones discursivas de los políticos, de los ciudadanos o los medios de comunicación, sino que

determinaría asimismo, más allá de los dichos, escritos e imágenes, las acciones políticas, las operaciones militares, el ruido de las armas, el estruendo de las explosiones y de las matanzas, las muertes de militares y civiles, los actos denominados de guerra o de terrorismo, de guerra civil o internacional, de guerra de partisanos, etc., con condena a muerte o sin ella según la ley. (Derrida, 2010:58)

\section{La differance del logos}

La noción de differance, que es también una metodología y una clave capital de toda la filosofía derridiana, Derrida la desarrolla por primera vez en un ensayo de 1968. Differance/Différence es un juego de palabras, donde hay una diferencia escrita que no se oye, que vuelve necesario pasar por la escritura, el significante empírico material, para entender el significado. Se trata de una intervención gráfica, calculada, en el proceso de interrogación sobre la escritura, que constituye una estrategia que Derrida utiliza para demostrar la ilusión que es el logofonocentrismo; para el cual, por un lado, está el significado ideal que está en el «alma» y, por el otro, el significante externo, muerto, indistinto al significado. Este silencio de la diferencia gráfica entre la «e» y la «a» señala que no existe escritura fonética o que esta no es más que una ilusión, porque si es cierto que para que la phoné pueda existir, hay que pasar por la escritura, entonces no hay escritura que sea una simple traducción de un pensamiento que exista anteriormente. Según Derrida, de esta oposición entre logos y escritura, se derivan el resto de las oposiciones en la historia de la filosofía, como la de sensible/inteligible, donde el logos sería lo inteligible y la escritura lo sensible. Pero si es cierto que hay que pasar por la escritura, lo sensible, para que el significado se produzca, tal oposición 
no existiría, sino una contaminación. Así que la diferencia marcada entre la «a» y la «e», es una estrategia que Derrida utiliza para desnudar la necesidad de ir más allá de esta oposición.

A diferencia de difference, que es, a grandes rasgos, un instrumento de signos que ha sido utilizado por la historia de la filosofía para marcar oposiciones entre las cosas, la différance derridiana es, en cambio, un movimiento, que es el movimiento del diferir de sí mismo (como por ejemplo el logos que pasa la escritura, haciéndose otro respecto a sí mismo) que es, para Derrida, la estructura misma de todas las cosas y, por lo tanto, también de las oposiciones de la metafísica, que más que oposiciones son contaminaciones donde cada término pasa por su contrario y se contaminan.

Para pensar este movimiento de contaminación en el que todo sí mismo llega a ser otro, Derrida retoma la etimología de la palabra difference. Por un lado, differe, del latín, diferir, es temporizar: dejar para más tarde, recurrir consciente o inconscientemente a la mediación temporal y temporizadora de un rodeo que suspende el cumplimiento o la satisfacción de un deseo o de la voluntad. Por otro lado, el significado etimológico del griego, diafren, es espaciamiento: un abrirse distancia respecto de sí mismo, procesos en los que la identidad difiere, implicando, por ello, el conflicto de descubrirse como otro respecto de sí mismo, en distancia respecto de sí. Si la différence de la historia de la filosofía nunca ha podido referir a estos sentidos etimológicos mencionados, existen, sin embargo, algunos pensadores como lo son Saussure, Nietzsche, Heidegger y Freud, ${ }^{2}$ que han permitido, para Derrida, sacar a la luz la differance y que constituyen, efectivamente, sus antecedentes filosóficos.

Con respecto al logos, que es otro nombre del «yo», de la racionalidad, de la ley; lo que dice Derrida es que no hay logos sin figura y viceversa, pues están en una relación de contaminación, en la differance, entonces, en el sentido derridiano del término. Ahora bien, si consideramos además que "figura», etimológicamente, del latín fingere, significa ficción y que es la condición de posibilidad del logos —que siempre ha sido considerado como la «Verdad»—, esto significa que existe una cierta contaminación entre verdad y mentira que nos lleva frente a una deconstrucción de la oposición verdad/mentira clásica en la tradición filosófica occidental. En Historia de la mentira. Prolegómenos (2015), Derrida se refiere a los fantasmas, los simulacros, los espectros, como entidades que se encuentran más allá de esta oposición entre verdad y mentira.

En La bestia y el soberano (2010), por su parte, Derrida dice que la figura es un fantasma y que es un fantasma en el sentido del psicoanálisis. Entonces, en cuanto a la manera en que la figura sutura el abismo del logos político al que este se va a caer en el momento de realizar su propia teleoescatología y tratar de ser lo que es, o sea una entidad que se abstrae de su propia materialidad, se había dicho ya que se trata de una solución tropológica, porque efectivamente es el tropos lo que simula; ahora podemos agregar que si la figura sutura el abismo en el que el logos político se va a caer es porque opera de una manera fantasmática.

\section{La lógica del fantasma y la pulsión de poder en la lectura derridiana del psicoanálisis}

Según el Diccionario de psicoanálisis (2004) de Laplanche y Pontalis, el fantasma es una construcción alucinatoria que permite la satisfacción de un deseo inconsciente, aun si lo hace de manera deformada, pues este deseo no se expresa de manera directa. Según el Diccionario, se trata de un concepto que desafía la tópica psicoanalítica, porque es consciente e inconsciente al mismo 
tiempo, puesto que permite la satisfacción de un deseo inconsciente, pero al mismo tiempo hay una elaboración que le impide al deseo de manifestarse como tal. A ello se debe que el fantasma pueda ser considerado como el lugar de la differance en el psiquismo, es decir, allí donde las varias instancias psíquicas difieren la una en la otra y se contaminan.

En el psicoanálisis freudiano, nos encontramos así frente a una especie de aporética del sistema psíquico, ya que la relación entre los «procesos primarios» (aquellos procesos que tratan de realizar la descarga de la energía) y los "procesos secundarios» (procesos mediante los cuales el psiquismo se vuelve capaz de controlar su propio impulso y de procrastinar el momento de la satisfacción) — que son, según Freud, los dos procesos mediante los cuales funciona el psiquismo-, es una transición que nunca llega efectivamente a cumplirse, que tropieza sobre sí misma. En este sentido, si los procesos primarios —que nos empujan hacia la producción de una alucinación que pueda enfrentarnos a la frustraciones frente a la imposibilidad de la satisfacción inmediata de los deseos-, operan a lo largo de la vida; se desprende de aquí que nunca se llega a salir de lo fantasmático, sino que, por el contrario, lo fantasmático estructura, en un sentido psicoanalítico, toda la experiencia humana.

Asimismo, si el fantasma, en el marco del psicoanálisis, es la satisfacción de un deseo inconsciente - tal como se desprende de la obra de Freud, particularmente «Formulación sobre los dos principios del acaecer psíquico» (1991), y de la definición de la Diccionario del Psicoanálisis (2004) mencionada anteriormente- se deduce que el concepto de fantasma está relacionado al concepto de inconsciente, concebido por Freud como una especie de contenedor de libido que funciona según el conjunto de los procesos (primarios) que buscan satisfacer la descarga de energía (realizar el placer), utilizando su propia lógica que, a diferencia de la lógica de la filosofía clásica, no conoce la contradicción, la negación, el tiempo, la muerte, etcétera.

Retomando la cuestión del abismo del logos político, esta lógica del inconsciente resulta fundamental para comprender la función de la figura (fantasma), pues cuando la razón se enfrenta al abismo - siguiendo una lógica de no contradicción por la que frente al abismo no puede negar el abismo, y al que, por lo tanto, se va a caer-, se contamina con aquello que rechaza, o sea con la figura, que está vinculada al inconsciente y por lo tanto a la lógica del inconsciente (de no-contradicción) que le permite simular la caída, enmascarar el abismo, puesto que lo que es un abismo puede ser también su contrario y, de esta forma, lo que era una caída en sí misma deja de serlo. Es así que, mediante esta lógica del inconsciente, lo figural sutura el abismo al que la racionalidad, el logos, se caería sin esta contaminación.

Al preguntarse cuál es el deseo soberano específico que este fantasma satisface y cuál es la deformación que está en juego, Derrida (2001) nos lleva a introducirnos en otro concepto freudiano que es el de "pulsión de poder», el cual, a pesar de su marginalidad en la obra de Freud, es para Derrida un concepto central y trascendental, porque está al cruce de todos los otros conceptos freudianos y es la condición de posibilidad del psiquismo.

A grandes rasgos, la pulsión de poder es, para Derrida, un movimiento, que es el movimiento con el que la vida trata de volver a su propio origen. Este origen es la muerte, dice Freud y lo justifica argumentando: al principio la vida era materia inorgánica, sin vida, sin estímulo, sin libido, sin animación, en donde la energía está a nivel cero, sin ningún estado de excitación. Si el objetivo de la vida es la muerte, entonces el curso que hay que hacer para volver al origen es la descarga de la energía. Sin embargo, este no es directo ni simple, puesto que Freud se refiere a una muerte 
en particular, que es la propia muerte del organismo, su muerte inmanente, para lo que resulta necesario rechazar la muerte contingente y volverse capaz de retrasar la pulsión de muerte.

Esta pulsión de poder que consiste en volver al origen — que puede tomar la forma de una pulsión de muerte (de la que Príapo sería un paradigma), aunque pulsión de poder y de muerte no coinciden exactamente- es el deseo que es satisfecho por el fantasma soberano.

La deformación específica que caracterizaría a este fantasma tiene que ver con el conflicto que la pulsión de poder vive con respecto a sí misma, con su propia tendencia a la descarga que amenaza lo que el logos político mismo es, es decir, logos soberano, dominio de sí: ¿cómo puede dominarse a sí mismo alguien que trata de satisfacer una tendencia a la descarga energético-libidinal? Si la pulsión de poder decide tomar el curso más rápido para llegar al origen (descargar la energía en la forma de la pulsión de muerte), ve amenazado su estatuto soberano, su control sobre sí misma, y es por esto que está en conflicto con aquella parte de sí que la empuja a la descarga inmediata. Es decir, la pulsión de poder está en conflicto consigo misma porque, por un lado, existe una tendencia que la empuja a descargar la energía para volver al origen y, por el otro, tiene que administrar esta energía, porque sino, al satisfacer la pulsión de muerte, deja de ser una pulsión soberana. En «Especular - sobre Freud» (1992), Derrida dice que el mecanismo por el cual se trata de controlar esta tendencia a la descarga que amenaza el control sobre sí mismo, que son los procesos secundarios, es en cierto sentido el mecanismo elemental del poder, al que todas las formas de poder que existen pueden ser reducidas. Y es en el momento en que aquella energía que tiene que ser descargada es controlada, sometida, ligada, que se constituye, mediante esta ligadura, un fantasma que es al mismo tiempo "paranoico» $\mathrm{y}$ «narcisista».

En sentido psicoanalítico, "paranoia» se refiere a la estructura que se produce en el momento en que el sujeto vive el conflicto respecto a su propia pulsión. En el caso específico de la pulsión de poder, que trata de restaurar la condición originaria (la muerte), amenazando su soberanía, se genera el conflicto consigo mismo, al rechazar a una parte de sí, a su propio deseo y también a los objetos del deseo, a los cuales va a juzgar como los que efectivamente despiertan la pulsión, percibiéndolos como objetos de persecución que deben ser neutralizados y que al final van a ser sometidos a una descarga de libido desexualizada.

Por otra parte, el «narcisismo» se produce, según Freud (1991), en el momento en que la libido del sujeto cambia su consistencia. Y distingue dos tipos de narcisismos: el narcisismo primario, que sería aquella tendencia mediante la que el sujeto rechaza la dependencia emotiva hacia su objeto e invierte la libido sexual en libido yoica dirigida sobre sí o la imagen de sí; y el narcisismo secundario, que actúa en contextos sociales de relación con los otros, que sería un investimento libidinal sobre imágenes sociales con las que el sujeto se reconoce, donde la violencia que normalmente se expresa en el narcisismo primario con respecto a los objetos de deseo (la libido desexualizada), se expresa, en cambio, contra aquellos otros que no se reconocen, por ejemplo, con una determinada imagen de la comunidad como puede ser la nación. En ambos casos, el carácter imaginario es constitutivo del narcisismo.

El fantasma soberano, que es un fantasma paranoico y narcisístico, al mismo tiempo es, según Derrida, la forma que ha tomado el poder en el canon ontoteológico político, cuya crueldad se explica mediante esta construcción fantasmática. Asimismo, existe a su vez, una contracara escondida, una diferencia intrínseca a las dos caras del fantasma, al narcisismo y a la paranoia, que ha sido rechazada por la filosofía y que la anarqueotropología permite sacar a la luz. Para 
dar cuenta de esto, y considerando que el narcisismo se construye mediante imágenes, podemos retomar la teoría de la imagen de Louis Marin, colega contemporáneo y amigo de Derrida.

\section{El fracaso del fantasma narcisista paranoico}

Lo que hace una imagen, según Marín (1981), es representar, donde «re» significa, etimológicamente, al mismo tiempo, reproducir y producir (el origen que la imagen representa). Con relación al narcisismo, esto implica que el sujeto empírico que trata de identificarse con su propia imagen ideal nunca llega a coincidir completamente con ella. Esta especie de diferencia que hay entre el uno y la otra puede ser considerada como una cierta frustración del narcisismo, una imposibilidad de realizar el deseo narcisista.

Según Marin, existe una dialéctica entre opacidad y transparencia característica de cada imagen. En la historia de la filosofía occidental, desde el pensamiento platónico en adelante, el gesto - que culminó con la perspectiva renacentista — ha sido el de volver la imagen transparente, donde transparencia significa «aparecer mediante», para que la referencia pueda aparecer. Pero la imagen no es completamente transparente, porque existe una materialidad, una superficie, un soporte, que necesariamente tiene que estar para que ella pueda representar. Y esta materialidad es, de cierta manera, lo que testimonia la diferencia que existe entre el sujeto y su imagen. La desreferencialización de la imagen (que significa que ella funciona implicando la borradura de su propio referente empírico) es, según Marín, el poder de la imagen de condenar a muerte al referente y, más radicalmente, en dar la muerte al referente, en hacerlo morir; un poder que la tradición filosófica siempre ha tratado de esconder reduciendo la imagen a simple copia de un origen.

$\mathrm{Al}$ considerar estas características de la imagen que se desprenden del pensamiento mariniano (que es productiva y reproductiva, opaca y transparente, y desreferencializada), nos encontramos ante un fracaso del narcisismo, que en teoría se satisface mediante la imagen, pero que, en realidad, al mismo tiempo que esta permite su constitución, lo deconstruye desde su interioridad, condición a la vez de posibilidad y de imposibilidad del narcisismo. La imagen, dice Marín, funciona como un otro, puesto que, si consideramos el hecho de que la imagen que permite la satisfacción del narcisismo nunca permite realizar esta satisfacción plenamente, para hacerse a sí mismo, el sujeto debe pasar por un elemento exterior, por un otro respecto a sí. Con lo cual, en todo caso, la satisfacción del narcisismo es un «cumplimiento imaginario» del deseo, que no se realiza en el nivel de lo real, porque al no haber coincidencia, este cumplimiento siempre está por venir. Marin retoma aquí la differance derridiana para dar cuenta de cómo el narcisismo difiere de sí, por un lado en el sentido de espaciamiento, dado el conflicto del narcisismo consigo mismo (ya que nunca llega a cumplirse), y, por el otro y al mismo tiempo, de temporalización, debido a que la satisfacción es siempre retrasada.

Desde un punto de vista económico libidinal, en el momento en el que la imagen difiere y no permite la satisfacción del deseo narcisista, la libido yoica tiene que convertirse en libido sexual (debido a la ley de proporcionalidad invertida según la cual cuando aumenta la libido yoica, disminuye la sexual y viceversa) dirigiéndose nuevamente hacia los que eran objetos de una libido desexualizada. Y aquella libido que era desexualizada cambia su movimiento y se dirige sobre el sujeto tomando la forma de un masoquismo, que puede ser considerado, en un cierto sentido, como el fantasma del fantasma narcisista paranoico, o su contracara. Es decir, si la cara oficial, pública, del narcisismo paranoico es el delirio de grandeza, el amor de sí y la destrucción del 
objeto, la contracara de este fantasma (que no tiene que ser entendido en un sentido cronológico como si hubiera un antes y un después), es efectivamente el masoquismo y el establecimiento de un vínculo afectivo con el otro por la conversión libidinal.

Esta conversión libidinal es, para Derrida, ya la differance, el movimiento que se deriva de la contaminación, en el sentido de que la libido yoica se contamina, difiere de sí y toma los rasgos de una libido sexual, así como la libido desexualizada más que ser exteriorizada se vuelve interiorizada, mediante un proceso de alteración que es exactamente la differance y que se realiza en el marco de la pulsión de poder. En el momento en el que la pulsión de poder se satisface fantasmáticamente mediante el fantasma narcisista paranoico, realiza la differance entre procesos primarios y secundarios, entre pulsión de vida y pulsión de muerte, entre principio de realidad y principio de placer, entre economía libidinal y economía general y viceversa. De aquí se desprende por qué para Derrida la pulsión de poder es un concepto trascendental en el psicoanálisis, en tanto condición de posibilidad de todos los otros conceptos freudianos, por ser el lugar en el que cada uno difiere de sí tomando la cara del otro.

Si la pulsión de poder, que es el origen del poder, difiere en sí misma, no hay condición de posibilidad para la ipseidad en la pulsión de poder. Entonces no hay poder, sino solo diferencia de poder, efecto de poder. No hay instancia ipsocéntrica, sino una differance de fuerzas que le impide al poder identificarse como ipseidad. Es por esto que, en el momento en que la pulsión de poder se satisface en su fantasma, se expresa el desmontaje intrínseco del poder que efectivamente la figuración misma produce.

En este sentido, si las revoluciones que hemos conocido en la historia han sido posibles es, para Derrida, porque ya habían empezado anteriormente dentro del poder por esta especie de desmontaje intrínseco que se realiza en el momento en el que el poder y su estructura pulsional se satisfacen en el fantasma que fracasa empujando al poder a dividirse. Pues, si la indivisibilidad forma, analíticamente, parte del concepto de soberanía, una soberanía divisible o compartible no es una soberanía. Y demostrar que la soberanía es divisible, que se divide y se parte y reparte es, según Derrida, ya parte de la deconstrucción de un concepto puro de soberanía. Una deconstrucción «lenta y diferenciada», dice, para señalar que el ritmo de esa deconstrucción es ante todo el ritmo de lo que ocurre en el mundo. Esa desconstrucción es lo que ocurre... Por eso «lenta», y, sobre todo, «diferenciada», pues en modo alguno se trata de oponerse pura y simplemente, frontalmente, a la soberanía: «No hay LA soberanía ni EL soberano. No hay LA bestia y EL soberano. Hay formas diferentes y a veces antagónicas de soberanía; y siempre se ataca a una de ellas en nombre de la otra» (2010:103).

En cuanto a la revolución, Derrida dice que cada revolución para que pueda acaecer, antes de que sea una revolución política, tiene que ser una revolución poética.

\section{Poética celaniana en la lectura de Derrida}

Según Derrida (2010), la poética de Paul Celan nos ofrece una concepción paradigmática de la poesía. En la sesión octava y décima de La bestia y el soberano, Derrida analiza el poema «El meridiano», en el que Celan retoma la "La muerte de Danton» de Büchner, particularmente un personaje que tiene un papel marginal, que es Lucile, la mujer de un hombre que es condenado a muerte en la época de la revolución francesa y que luego de que mataran a su marido, va a la plaza de la guillotina y empieza a gritar «iviva el Rey!» y se hace matar. Celan cree reconocer en este 
grito de la Lucile de «La muerte de Danton» como acto de libertad, la poesía misma. Retomando este discurso de Celan, Derrida plantea que este grito es la palabra del otro, de lo extraño, porque es efectivamente lo que dice algo que no se podía tolerar en el marco del contexto revolucionario; es el otro con respecto a este contexto sin que esto signifique que sea la palabra conservadora que trata de profesar la restauración monárquica. En este sentido, en esta experiencia, Derrida reconoce la palabra poética, de lo absurdo y de lo que no se deja integrar en el marco de un sentido codificado en cuanto sentido de un contexto cultural, político, social, etcétera.

El soberano, que es el único que se autonombra, que se refiere a sí mismo, ipse, a su título, a su nombre y a su fuerza, a su ipseidad, que todavía no es ni un «Yo» ni un individuo, ni un nosotros ni una comunidad, es un «quien» antes de cualquier "yo», cualquier individuo, cualquier persona, cualquier nosotros y cualquier comunidad, de modo que la pregunta acerca del propio ser del ser humano ya no es ¿qué es?, sino ¿quién? Al final, la cuestión del arte, o de la poesía como arte, que atraviesa todo «El Meridiano», es, según Derrida, la cuestión de la técnica en cuanto venida o aparición de un quién y de un qué técnico... «Atemwende», diría Celan, que no es solo el título de uno de sus libros de poesía, sino la palabra que utiliza en «El Meridiano» para intentar una definición de la poesía como un «vuelco del aliento», primero y último signo de la vida viviente. «Sin duda, no hay palabra ni silencio que hable sin aliento pero, antes de la palabra y al principio de la palabra, estaría el aliento» (Derrida, 2010:260).

A través de ese poema sobre la poesía que es «El Meridiano», el discurso celaniano, deja entrever una doble división: por una parte, una primera diferencia, disociación o división entre la majestad del Monarca (del Monarca Luis XVI, aquel que perderá su cabeza) y la majestad de la poesía; y, por otra parte, la división en la presencia misma del presente en el poema como encuentro.

La disociación, pues, la partición que también es un reparto, entre mi presente, el presente mismo, la presencia misma del presente, del mismo presente, en el presente de lo mismo y, por otra parte - y ésta es la otra parte de la partición y del reparto, el otro presente, el presente del otro a quien el poema hace presente de su tiempo, dejando así hablar, en un Mitsprechen, el tiempo del otro, su propio tiempo. (Derrida, 2010:309)

El secreto del poema, dice Derrida retomando la poética celaniana, es el encuentro, o el secreto del encuentro, en el del doble sentido de esta expresión: secreto, por una parte, de la génesis del poema, de su condición de posibilidad, que es, justamente, el encuentro; y, en segundo lugar, como aquello que en el ahora-presente de la presentación misma del poema permanece todavía secreto, un fondo que no se fenomenaliza, que no se deja nombrar y que es para Celan, justamente, la poesía.

Según Derrida, Celan precisa que en el ahora-presente del poema (el aquí-ahora puntual del Yo), se debe dejar hablar al ahora-presente del otro, al tiempo del otro; introduciendo, de este modo, una divisibilidad o una alteridad en el ahora-presente que hace que haya que releerlo todo acerca de la autoridad predominante, que se convierte en un compartir disimétrico con el otro. Este vínculo (con el Tú en el encuentro) es aquello que se busca en un camino que Celan califica como «camino imposible» o «camino de lo imposible».

¿acaso no vemos que el poema, ya aquí, tiene

lugar en el encuentro - en el secreto del encuentro? 
El poema quiere ir hacia Otro, necesita de este Otro, lo necesita frente

a él. Lo busca, se promete a él.

Cada cosa, cada ser humano es, para el poema que ha puesto así rumbo hacia el Otro, una figura de ese

Otro. (Celan «El meridiano», citado en Derrida, 2010:312-313).

Esta salida fuera de lo humano, que se trata de transportarse a un terreno que vuelve hacia lo humano su lado extraño y que Celan describe como se describe el gesto o el movimiento del otro, sería lo «propio del arte», pero de un arte que sería extraño, una extrañeza familiar, — «unheimlich», según Büchner-, porque, en ese arte, se encontrarían «en su casa» cosas aparentemente inhumanas. Celan se pregunta, así, si la poesía debe o no tomar el camino de un arte que sería asimismo el de la Medusa y de los autómatas.

Todas las aproximaciones —-múltiples — de lo que sería la poesía son, todas ellas, aproximaciones no de una esencia sino de un movimiento, de un camino y de un paso, de una dirección, de un vuelco en dirección al paso así como de un vuelco en el aliento mismo (Atemwende). (Derrida, 2010:317)

Al pensar la poesía como un camino, que no es tanto algo que «es» cuanto un acontecimiento, la venida de un acontecimiento que llega, Celan evoca, según Derrida, la oscuridad propia de la poesía como el lugar de un encuentro por venir desde el horizonte de lo lejano y de lo extranjero. Finalmente, lo que muestra Derrida en La bestia y el soberano es cómo Celan apunta hacia una alteridad que, dentro del «Yo» (de ese poder decir «yo», que en la tradición filosófica siempre ha estado explícitamente reservado al ser humano $)^{4}$ como presente viviente puntual, como presente viviente presente a sí mismo, una alteridad radicalmente otra viene, no a incluir ni modificar otro presente viviente, sino a dejar aparecer el presente del otro.

Es como si, tras la revolución poética que reafirmaba una majestad poética más allá o fuera de la majestad política, una segunda revolución, la que corta el aliento o vuelve el aliento del revés en el encuentro con lo radicalmente otro, viniese a intentar o reconocer, a intentar reconocer, incluso, sin conocer ni reconocer nada, a intentar pensar una revolución en la revolución, una revolución en la vida misma del tiempo, en la vida del presente viviente. (Derrida, 2010:323)

\section{Reflexiones finales}

La poesía es entonces, para Derrida, lo que nos enfrenta a la experiencia del otro, al contacto con la alteridad, lo perturbador y lo extraño que nos lleva más allá de lo humano. En este sentido, la experiencia de lo poético es la misma que en lo fantasmático, porque se hace la misma experiencia de la alteridad. Pues, como hemos visto, la pulsión de poder difiere de sí, ya que el fantasma en el que la pulsión de poder se satisface al final no es otra cosa más que una diferencia del narcisismo respecto a sí mismo que fracasa en el momento en el que la imagen, en razón de su diferencia, impide satisfacer la libido yoica, convirtiéndose en libido erótica que se dirige hacia los objetos donde estaba descargada la libido desexualizada que ahora no puede estar más allí, por lo que es interiorizada y dirigida sobre la imagen de sí como pulsión de muerte destructiva. Es aquí, efectivamente, que se hace una cierta experiencia del otro, porque la interiorización de la pulsión de muerte implica la autodestrucción de la defensa del sujeto, exponiéndolo de manera 
vulnerable al acontecimiento del otro. Esta inevitable reconversión de la libido desexualizada (la pulsión de muerte interiorizada, que es la pulsión de poder que toma esta forma masoquista y destruye su propia defensa), que implica la exposición al acontecimiento del otro es un mecanismo intrínseco a la vida pulsional misma en general.

Así, la fuerza que Derrida descubre dentro de la pulsión de poder como differance de fuerzas, que se deriva de esta destrucción de la defensa, es una fuerza sin poder, que excede la oposición entre pasividad y actividad: no es pasiva porque no se trata de estar expuesto al acontecimiento del otro, sino de decidirse para eso y de dejarlo acaecer, y este «dejar» es un acto; pero tampoco es activa, porque no se hace acaecer al otro, sino que se lo deja venir, se abre paso a la venida del otro. Esta fuerza sin poder, dice Derrida, es paradójicamente capaz de hacer lo imposible más que lo simplemente posible (que es lo que puede hacer el poder). La desactivación de la defensa es la desactivación del poder y, por lo tanto, la posibilidad de dejar acaecer al otro, que es efectivamente lo imposible, lo imprevisible, lo incalculable. Esta fuerza sin poder que es la fuerza de dejar venir lo imprevisiblemente otro, de hacer lo imposible, que hace que la fuerza sin poder sea fuerza sin poder pero no sin fuerza, es exactamente lo que se sucede en la experiencia poética, y es aquí que se sitúa toda la apuesta emancipadora de la deconstrucción.

Esta venida del otro, que se sustrae a toda programación es todavía una invención porque se prepara, se hace ese paso destinado a dejar venir al otro que no es sujeto ni objeto, ni un yo, ni una conciencia, ni un inconsciente. Una invención deconstructiva, «otra invención en la que soñamos, la de lo totalmente otro, la que deja venir una alteridad aún inanticipable y para la cual ningún horizonte de espera parece aún listo, dispuesto, disponible» (Derrida, 2015:123). Ese hacer considerado como "poesía», que "se sostiene agazapado como un animal, tensado como un resorte, y ya así en acto» (Nancy, 2013:163), preparando la venida del otro mediante la manipulación obstinada de una lengua apócrifa que hace saltar el sentido, es, según Derrida, una experiencia de la alteridad, porque nos enfrenta a la presencia del otro, lo extraño y más allá de lo humano, al igual que el fantasma narcisista paranoico que difiere de sí mismo como solución siempre retrasada del poder a través de un proceso de diferimiento libidinal y pulsional, donde el desmontaje del poder aparece dentro del poder y no fuera de él, tal como se expresa en el momento en que la pulsión de poder se satisface en su fantasma, y lo figural mismo hace que el poder, el logos político, la norma, se desmonte.

\section{Notas}

1 En cierto sentido, lo mismo ocurre en el caso del «yo». En un ensayo sobre Valery, «Qual. Cuál. Las fuentes de Valéry», en Márgenes de la filosofía), Derrida analiza esa fuente de la que habla Valery que es el «yo» (haciendo referencia al pensamiento subjetivo, lógico, a la racionalidad del sujeto humano). En el marco del pensamiento de Valery, el yo es un yo «desnudo», en el sentido de que se trata de pensar el pensamiento como lo que existe antes de cada revestimiento sociocultural, en una especie de arqueología en la que se trata de eliminar toda la determinación «exterior» o de neutralizar toda dimensión

empírica para ver qué es en el fondo este «yo puro». Y al final, ¿qué nos queda de este yo? Esta fuente no es nada, dice Derrida, pues un pensamiento que se quiere puro, que es totalmente abstracto, que no está vinculado a la existencia empírica, a la materia, se vuelve al final una especie de quimera, y es aquí que se abre el abismo, en cuanto a que si en el lugar del fundamento hay una entidad que es evanescente, no hay un fondo o un suelo, sino un vacío, un abismo. El yo no es nada fuera de su metáfora, ni más allá de la metáfora, ni más acá de lo que lo transporta fuera de sí. Entonces, por un lado, la metáfora 
soluciona el abismo y entonces le permite al yo, ser de cierta forma, pero este no se manifiesta por lo que es en sí mismo sino que se manifiesta mediante otro, que es el dispositivo figurativo, por lo que en cierto sentido sale afuera de sí, al igual que el logos político, la razón, la soberanía. Así, para hablar de la fuente de Valery, de este yo desnudo, de la racionalidad pura, del logos, es necesario volver mediante un tropos.

2 Según Derrida, Saussure permite pensar una differance como temporización y como espaciamiento en la problemática semiológica del algoritmo de significante/significado: el significado no es nada en sí mismo, sino por el hecho de estar vinculado con otros conceptos, y lo mismo pasa con el significante. Es decir, una diferencialidad vinculada a la doble cara del signo que Saussure desvela; y por lo que Derrida lo considera un pensador de la differance.

En Nietzsche, o la lectura derridiana de Nietzsche, la vida o el sujeto serían una differance de fuerzas, en relación las unas con las otras, donde el sujeto sería el resultado de estas relaciones inestables de fuerzas. De hecho, el mismo Nietzsche, ya en El origen de la tragedia, denuncia a la tradición filosófica occidental desde Sócrates en adelante, de haber hecho prevalecer lo apolíneo (o fuerza de la razón) sobre lo dionisíaco (como fuerza de vida, de éxtasis), reduciendo y neutralizando la differance de fuerza en favor de lo apolíneo.

Heidegger y fundamentalmente el concepto heideggeriano de la diferencia ontológica entre el ser y la presencia del ente, a la que el ser no se deja reducir, escapando a todas las representaciones subjetivas, permiten, para Derrida, pensar en la differance. No hay una línea de oposición ontológica entre el ser y el ente, sino el movimiento del diferir del ser en el ente, el movimiento de sustitución del ser en su propio significante, en una huella, en un signo.

Con respecto a Freud, si bien él individualiza ciertos conceptos con los que explica el funcionamiento del psiquismo, por ejemplo: pulsión de vida y pulsión de muerte, principio del placer y de la realidad, etc., que hace parecer que estamos frente a un conjunto de oposiciones; en realidad, todos estos conceptos, ya sean pulsiones o principios, considerados en sí mismos, sin la vinculación con el resto de los conceptos, son — como el mismo Freud afirma— «ficciones teóricas», abstracción, porque en la dimensión concreta de la vida no hay entidades o instancias pulsionales o libidinales puras. Para
Derrida, Freud puede ser considerado un antecedente de la differance ya que desvela el movimiento del diferimiento de las pulsiones de muerte y de vida, y lo mismo se puede decir con respecto a los otros conceptos freudianos como el principio de placer y principio de realidad.

3 En algunos capítulos de La bestia y el soberano, Derrida parece encontrar una especie de paradigma mitológico y literario de la pulsión poder que se cumple descargando la energía en la forma de una pulsión de muerte. Esta figura mitológica es Príapo, que, como dice Derrida, se encuentra también en una obra de Freud, «El tabú de la virginidad», donde aparece esta figura mitológica como una marioneta fálica. Príapo es el hijo de Dionisio y Afrodita, que se caracteriza por tener un falo siempre erecto, itifálico. Es por este itifalismo que este personaje es el paradigma o el arquetipo mitológico literario de la pulsión de poder que trata de descargar la energía libidinal sin control, pues una erección constante es una ausencia de control y un rechazo a la castración, que, en el marco del discurso psicoanalítico, es la aceptación de un límite: aquella aceptación del límite de la que el niño tiene que hacerse cargo para establecer relaciones sociales con los otros. En el momento en que no se acepta la castración, lo que se produce es una especie de psiquismo que trata de llegar a un goce pleno, que es más allá de la experiencia humana. El rechazo a la castración en el psicoanálisis tiene el nombre de fetichismo. Y es por esto que se puede decir que si Príapo es el paradigma de la pulsión de poder que puede tomar la forma de una pulsión de muerte, entonces esta pulsión es una pulsión itifálica y fetichista.

4 Poder decir «yo» que es, en la lectura derridiana de Lacan, otra cara del sometimiento del sujeto al significante. Ser sujeto del significante quiere decir, pues, dos cosas indisociables que se acoplan en la subjetividad del sujeto: el sujeto del significante está sometido al significante, al orden simbólico que le es constituyente, sobre la cual no tiene dominio ni soberanía. Pero, por otra parte, ser sujeto del significante es también ser sujeto que somete, sujeto amo, sujeto activo y que decide del significante. Esta soberanía es la superioridad del humano sobre la bestia, aunque esta superioridad se asegure desde el privilegio del defecto, de la carencia o de la falta en virtud de la cual el humano es sujeto del significante, sujeto sometido al significante soberano. 


\section{Referencias}

Derrida J. (1968). La diferencia. Edición electrónica de www.philosophia.cl / Escuela de Filosofía Universidad ARCIS. https://www.ddooss.org/articulos/textos/Derrida_diferencia.pdf

Derrida J. (1992). Especular - sobre Freud. La tarjeta postal: de Sócrates a Freud y más allá. México: Siglo XXI.

Derrida J. (2001). Estados de ánimo del psicoanálisis. Buenos Aires: Paidós.

Derrida J. (2003). Qual. Cuál. Las fuentes de Valéry. Márgenes de la filosofía. Madrid: Cátedra.

Derrida J. (2005). Canallas. Dos ensayos sobre la razón. Madrid: Trotta.

Derrida J. (2010). La bestia y el soberano. Volumen I. Buenos Aires: Manantial.

Derrida J. (2011). La bestia y el soberano. Volumen II. Buenos Aires: Manantial.

Derrida J. (2014). Psyqué. Invención del otro. Psyché. Invenciones del otro. Buenos Aires: La Cebra.

Derrida J. (2015). Historia de la mentira. Prolegómenos. Editorial Universitaria de la Facultad de Filosofía y Letras, Universidad de Buenos Aires.

Freud, S. (1991). Formulaciones sobre los dos principios del acaecer psíquico; Introducción al narcisismo. Obras completas. Volumen 12. Buenos Aires: Amorrortu.

Laplanche, J. y Pontalis, J.B. (2004). Diccionario de psicoanálisis. Buenos Aires: Paidós.

Marin, L. (1981). Le portrait du roi. París: Minuit.

Marin, L. (2005). Politique de la représentation. París: Kimé.

Nancy, J.-L. (2013). Hacer, la poesía. Badebec. Revista del Centro de Estudios de Teoría y Crítica Literaria, 3(5). https://revista.badebec.org/index.php/badebec/article/view/6o/55

Nietzsche, F. (2010). El origen de la tragedia. Buenos Aires: Terramar.

Schmitt, C. (2009). Teología política. Madrid: Trotta. 